Private blog reflections connecting course content with field experiences: Preservice teachers grapple with teacher identity

Corresponding author: Lauren Eutsler, Ph.D.

University of North Texas

Teacher Education and Administration

1155 Union Circle \#310740

Denton, TX 76203 - 5017

940-565-2539

lauren.eutsler@unt.edu

https://orcid.org/0000-0002-9869-0331

@laureneutsler

Co-author: Rachele Curcio, Ph.D.

University of South Carolina

Wardlaw, 107S

curciora@mailbox.sc.edu 
[Type here]

\section{Private blog reflections connecting course content with field experiences: Preservice teachers grapple with teacher identity}

\section{Introduction}

In response to the challenge faced by teacher educators to bridge educational theory with classroom practice (Argyris \& Schön, 1974; Korthagen, Kessels, Koster, Lagerwerf, \& Wubbels, 2001), this study addressed this complex process by infusing systematic reflective responses into an intermediate reading methods course using a private blog. This reflective practice was intended to cultivate preservice teachers' ability to reflect upon teaching and pedagogical content knowledge (Shulman, 1986) to better understand how perceptions and practices of reflection may contribute to becoming a professional teacher.

For our present study, we define reflective practice as intentional thinking to reflect on what has happened, within the context of making connections between field experiences and the higher education classroom. A weblog, commonly referred to as "blog" is a "cyberspace in which individual students create their own online diaries" (Wang \& Woo, 2008, p. 35).

An increasing number of refereed studies have investigated the use of blogs as a reflective tool in higher education (Yang, 2009). One reason for this increase may be that online communication tools afford a flexible, convenient, and collaborative social environment (Wang \& Woo, 2008).

While reflection has often been embedded as an instructional approach within teacher education programs, the National Council for Accreditation of Teacher Education's Report of the Blue Ribbon Panel (2010) explicitly called for teacher 
[Type here]

educators to prepare preservice teachers for the application of content and pedagogical knowledge through reflection and problem-solving focused on teaching and learning. Structured opportunities for reflection should be provided throughout all aspects of a program's coursework and clinical practice (Zeichner, 2009).

\section{Reflection in Teacher Education}

Reflection in teacher education is important because it provides a window into preservice teachers' perceptions and thinking about the complex journey of becoming a teacher. Promoting engagement in meaningful reflective thinking and viewing teachers as "reflective practitioners" (Zeichner \& Liston, 2013, Chapter 1, Section 4 para. 1) dates to the work of John Dewey. Reflection is constituted by the "active, persistent and careful consideration of any belief or supposed form of knowledge" (Dewey, 1910, p. 6). Dewey (1910) argued reflection on past experiences is required for educators to understand the outcomes or consequences of their actions. Reflective practice is a means for educators to increase self-awareness about their performance in a manner that creates opportunities for professional growth and development (Osterman \& Kottkamp, 1993).

Education "entails both thinking and feeling," and the ability to "reflectively think and feel" (Zeichner \& Liston, 2013, Preface, Section 5 para. 1) assists teachers in making informed and rational decisions about teaching and learning (Ross, Bondy, \& Kyle, 1993). Through reflection, teachers engage in "thoughtful reconsideration of all that happens in a classroom with an eye towards improvement" (Ross et al., 1993, p. 17). Essentially, reflective educators are committed to the education of all students and to their own education as teachers (Schön, 1983), and this commitment is pivotal for enhancing the effectiveness of novice teachers in our nation's diverse $21^{\text {st }}$ century 
[Type here]

classrooms (Gay \& Kirkland, 2003). Hence, it is not enough to assume that novice teachers will enter the classroom with the skills and dispositions needed to engage in meaningful, critical reflection focused on enhancing teaching and student learning. With this knowledge, teacher educators should strive to incorporate ongoing opportunities for reflection into all facets of teacher preparation programs (Feiman-Nemser, 2012; Grossman, McDonald, Hammerness, \& Ronfeldt, 2008; Zeichner \& Liston, 2013). One such example includes a study where preservice teachers explicitly journaled in response to "reflect on the life of the mind" (Mortari, 2012, p. 525).

Reflection is a process that has been applied to a variety of teacher education contexts, including literacy instruction. Interestingly, studies spread apart in time from one another have revealed reflective responses lacked depth and critical thought (Bednar, 1991; Shoffner, 2008). Of 60 preservice teachers enrolled in three reading courses, analyses of reflective writings contained unsubstantiated vague thought, with discussion expressing fear and emphasis toward envisioning themselves applying their reading knowledge in upcoming field experiences (Bednar, 1991). Measured by Zeichner and Liston's (1985) evaluative framework, Risko, Roskos, and Vukelich (2001) identified reflections as factual (stage 1) as opposed to prudential (stage 2) or justificatory (stage 3).

\section{Reflection in a Blog Space}

Previous attempts to include reflection in teacher education resulted in surface thinking but studies using a blog indicate promising outcomes. An early study (Stiler \& Philleo, 2003) on 63 preservice teachers blogging to embed greater levels of reflective practice resulted in reaction statements to course readings, activities, discussions, instructor and student presentations, and guest speakers. Analysis revealed "the depth and 
[Type here]

breadth of student reflectivity appeared to be positively affected by their use of Blogger" (Stiler \& Philleo, 2003, p. 795).

An eight-month examination of preservice teachers' use of blogs showed writings included informal thinking about personal experiences with mentor teachers and university instructors, analysis of current teaching practices, emotions tied to experiences, and predictions relating to experiences in future classrooms (Shoffner, 2008).

Implications from Shoffner's (2008) study show the importance of using explicit instructional strategies, such as reflective journals, to provide opportunities to engage in reflection. Another study indicated responses were reflective, with some evidence of critical reflection; reflective thinking occurred in response to active participation of the researcher, who asked probing questions and delivered feedback to support critical reflective conversation (Yang, 2009). Blogs have also provided peer feedback, which led to critical thinking and reflection. Feedback in the blog contained more critical comments than those who did not participate in the blog, measured by two-way repeated measures ANOVA (Novakovich, 2016). Collectively, studies which have instilled blog reflections indicate promising results toward engaging preservice teachers in higher levels of reflection.

\section{Theoretical Framework}

This study is framed and guided by Dewey's (1933) phases of reflective thinking and Schön's (1983) reflection on action as an ethic for inquiry. Dewey (1933) provides five approaches to thought: "reflective thought is a chain;" "thinking [is] usually restricted to things not directly perceived;" "reflecting thinking aims at a conclusion;" "thinking [is] practically synonymous with believing;" and, "reflective thinking impels to 
[Type here]

inquiry" (p. 4-7). Reflective thinking originates from a state of "doubt, hesitation, perplexity, [or] mental difficulty," (p. 12) which leads to an inquiry to resolve the doubt. Dewey (1933) contended reflective thinking cannot occur without suspense and search for intellectual thought. Reflective thought is an "active, persistent, and careful consideration of any belief or supposed form of knowledge in the light of the grounds that support it and the further conclusions to which it tends" (p. 9). Dewey's descriptions of thinking provides a framework for understanding how rising teachers should engage in purposeful reflection that captures their thinking about learning and the notion of becoming a future teacher of reading.

Schön's work expanded Dewey's examination of reflection as the ability to reflect on an action by how an individual performs in any given situation, positing reflection on action can be a tenet for inquiry (Schön, 1983). Schön's (1983) perspective of reflection is represented by the practitioner's appreciation system (e.g., possessed values, knowledge, theories, and practice) and surfaces as an unconscious interpretation of what is occurring. Particularly, reflection on action is one's ability to develop change based on what has happened, "we reflect on action, thinking back on what we have done in order to discover how our knowing-in-action may have contributed to an unexpected outcome" (Schön, 1983, p. 26).

Within this theoretical framework, the following research questions were asked: How do preservice teachers perceive reflection in the context of teacher education? How might systematic reflection influence the development of preservice teachers toward becoming classroom teachers?

\section{Method}


[Type here]

\section{Participants and Study Context}

Participants included 24 preservice teachers-23 identified as female, two as Black, two of Latina origin-enrolled in an intermediate reading methods course within an elementary teacher education program located in the southeastern United States. In all, 20 participated in the mid-semester survey, 23 responded to the post-semester survey, and all preservice teachers posted weekly blog responses.

The course was the second of two reading courses taken during the first semester of the third-year within a four-year undergraduate teacher preparation program. A course requirement included a field experience component of one day a week for 13 weeks in an elementary classroom. The program emphasized a reflective inquiry stance.

\section{Research Design and Data Collection}

A mixed-method research design (Creswell, 2013) allowed for examination of perceptions of reflection and examination of written blog responses. Data collected were approved by the university's IRB, with pseudonyms used to refer to participants' blog responses.

Blog responses. A private blog (Kidblog), accessed by individual passwordprotected logins, was used to capture and record blog responses. Following each of the 15 course meetings, preservice teachers used their mobile devices to post a written response to the blog. The task, entitled "Reading Wrap Ups," was open-ended, a purposeful structure to allow preservice teachers to close class with the systematic use of a blog for individual reflection.

Mid-semester and post-study surveys. Mid-semester and post-study surveys contained mixed-method response types to obtain perceptions of reflection. Survey items 
[Type here]

were informed by stages of reflection in teacher education literature (Roskos, Vukelich, \& Risko, 2001) while open-ended response types were constructed to evoke perceptions about reflection (Dillman, 2011).

Surveys were informed by Roskos and colleagues' (2001) levels of reflection: describe an activity; report on what happened in-class; ask questions; interpret an activity or lesson; evaluate an activity or lesson; critique an activity or lesson. In the midsemester survey, all responses were selected that captured the purpose of reflection, whereas in the post-study survey, participants had to choose only one response choice.

The mid-semester survey $(n=20)$ contained three items to measure preservice teachers' perceptions of reflection and future use. We asked, "what do you believe is the purpose of the Reading Wrap Up activity?" and "based on your experience with 'Reading Wrap Up' halfway through the semester, could you see yourself using the same or similar type of reflection strategy in your own teaching?" The latter question was followed by, "If yes, how might you envision yourself using this reflection strategy in your teaching?" and "If no, in the previous question you said you couldn't see yourself using this type of reflection strategy in your own teaching. Please explain your reasoning."

The post-study survey $(n=23)$ revisited perceptions of reflection and contained six questions. Response items addressed: 1) a definition of reflection, 2) perceptions of the daily reflective activity, 3) intent to implement a similar strategy, and 4) an open space to share additional information.

\section{Data Analysis}


Quantitative survey data were analyzed using descriptive statistics (e.g., frequencies, $M$, and $S D$ ) and qualitative data underwent inductive thematic analysis (Hatch, 2002). In all, 198 survey response items and 290 blog responses were examined.

Guided by Hatch (2002), we engaged in a seven-phase inductive thematic analysis. During phase one, we individually read the complete qualitative dataset, notating impressions, thoughts, and preliminary interpretations. Following our initial readings, phase two consisted of rereading all blog responses to inductively generate potential analysis domains (Hatch, 2002). From this analysis, each researcher compiled a list of potential domains.

In phase three, we collaborated on, compared, and contrasted our potential domain lists to determine meaning based on relationships within the data. All possible terms and phrases connected to our initial analysis were listed, and then terms and phrases were sorted based on connections and relationships. This discussion led to the creation of a collective list of 11 initial domains. Some initial domains included emotional responses, retelling course events, and judging instructor's pedagogy.

Phase four involved individually delving back into the dataset to determine whether all data fit within the initial domains, and identifying whether new domains were needed. This was accomplished by sorting data based on the 11 initial domains. Next, phase five involved collaboratively revisiting the data to examine terms, examples, and relationships within and across the domains to discover key themes. This deeper analysis resulted in the creation of three key themes.

Following the identification of the three themes, phase six consisted of individually color-coding the dataset to represent the identified themes. Our final phase 
[Type here]

served to ensure both a shared understanding of each theme. To do so, we discussed differences or confusions about coding and documented such thoughts and information, which allowed us to establish consistent interpretations across domains. As presented in our results, this collaborative conversation resulted in the determination of four final themes. Research memos and a graphic organizer were created to summarize thematic connections.

\section{Results}

\section{Preservice Teachers' Perceptions of Reflection}

The mid-semester and post-semester surveys addressed our first research question: How do preservice teachers perceive reflection in the context of teacher education?

Mid-semester survey findings. Mid-semester survey results revealed preservice teachers' perceptions of the written response experience through descriptive statistics (Figure 1) and open-ended response items.

[Figure 1 near here]

In response to open-ended survey item one, "What do you believe is the purpose of the Reading Wrap Up activity?" nearly half of responses indicated "reflect on what we learned in class." Others commented on the blog's affordances to "organize thoughts," "draw conclusions," "summarize," and "reference later." Some recognized the blog as a formative assessment tool, "for the professor to see if information is being taught," "to see if everyone is on the right track," and "to give our instructor an idea of what we took away from the lesson." Although prompted to choose all applicable statements to explain the purpose of blog responses, $91 \%$ indicated "to report on what happened in-class," 
followed by $70 \%$ who contended the purpose was "to evaluate an activity or lesson." In addition to gathering data on preservice teachers' perceptions on the purpose of the activity, 95\% said they would use a similar strategy in their future classroom.

In response to the open-ended item, "How might you envision yourself using this reflection strategy in your teaching?," analysis showed preservice teachers used the reflective strategy in three ways:

a) to measure student learning,

b) use a private blog to deepen thinking, and

c) facilitate collaboration both in and outside of the classroom.

Thirteen responses referred to the activity as an "exit slip," to be used "as an informal assessment tool." "It would be a way for me to tell what students got out of the lesson, what they struggled with, and what they enjoyed. I would use it to see what worked and what did not." For others, "students [can] voice confusions and problems that happened in class" and the teacher can "see if students need extra support in some areas."

The blog was described as a tool to extend learning where a teacher could "have students post remaining questions/big ideas" or "answer reading response questions." Responses also demonstrated how a private blog can increase collaboration because it "gives students an authentic audience," and provides a "platform for students to share their work digitally with each other" while completing "work on a group project." The blog could be "beneficial to share ideas" and provide "a place for students to ask questions to one another about homework and assignments."

Post-semester survey findings. In the post-semester survey (Table 1), 100\% of preservice teachers envisioned themselves using a similar reflective strategy. The post- 
[Type here]

semester survey asked preservice teachers to define reflection, choose the primary way they used the blog responses (Roskos et al., 2001), and respond to Likert-scale questions about the extent reflection should be a component of teacher education (ranging from 17; strongly disagree to strongly agree).

\section{[Table 1 near here]}

Preservice teachers' primary purpose of the reflective response activity was consistent in both surveys (Figure 2), indicated by $43 \%$ of responses "to report on what happened in-class," and 35\% agreement "to evaluate an activity or lesson."

[Figure 2 near here]

Responses to the open-ended item, "What is your definition of reflection?" indicated phrases synonymous with the word reflection. Retellings for reflection included "talking about what happened," "reflect on what you learned," "look back at what you just did or learned," and "restate what occurred." Reflection appeared as "explaining one's feeling towards something that is being done," to "thoughtful reproduction of learned material," "thought or consideration about a topic," and "writing down of one's meta-cognition after they have experienced something." Reflection was also viewed as "how you can connect it to other things," "what you will do about it," "thinking about something you've done and thinking about ways to make it better," and "incorporating it into schema." Reflection is "thinking critically and holistically upon a topic to put thoughts into words. Reflection usually entails some aspect of thinking about the next steps or the future in a constant cycle of action, reflection, and reaction."

Using the blog was a method of systematic reflection. "Synthesizing my ideas at the end of each class into a concise statement helped me to think more clearly about the 
[Type here]

topics discussed," and could be a "really great way to have students reflect each and every day." "It was a helpful way to reflect on each class as well as allowing you to see what we took away from the class." "Reflection was simple and straightforward," "getting practice with it in this class helped me understand its use," and this practice "allowed for the class to wrap up nicely."

Systematic use of the blog was recognized as a benefit to understanding reflective practice. Using the private blog was "a non-threatening way to respond to what we learned in class," "very well planned out," and a "great way to understand how to incorporate technology." "I enjoyed posting comments and reading what everyone else had to say." "I really liked the use of Kidblog in this class. I definitely think I will use it in my class one day as a reflection tool for my students."

\section{Influence of Systematic Reflection on Teacher Development}

Open-ended items from both surveys and ongoing blog responses addressed our second research question: how might systematic reflection influence the development of preservice teachers toward becoming classroom teachers?

Inductive thematic analysis of reflective blog responses provided insight into how the systematic use of reflection influenced the development of preservice teachers becoming classroom teachers. Four emergent themes captured preservice teachers experience with systematic reflection: visceral thought, vulnerability, processing to comprehend course content, and identity formation (Figure 3).

[Figure 3 near here]

Visceral thought. Most common were reflections described as visceral thought. Responses within this reflective level showed a positive sense of emotion that included 
[Type here]

motivation, enthusiasm, and enjoyment. A shared characteristic was a lack of support within the written reflection to justify or extend the expressed emotion.

Following the comprehension strategy instruction lesson on the first day of class, Harper communicated she "really enjoyed learning how to teach such an important subject," and elaborated on her enthusiasm to "learn more ways to teach and how to incorporate technology." After reading Harper's response, the instructor recognized her enjoyment toward the course but without supporting detail, was unsure what contributed to the enjoyable experience of learning about teaching reading. After a lesson on structural analysis and word study, Tawnie expressed similar excitement, indicated by how much she "loved the Pinterest board for the week" because "it was full of really useful information and made the class very engaging." Again the instructor understood the inclusion of the Pinterest board may have been helpful to clarify course content, and with visceral thought reflective responses, there were explanations of this excitement.

Similarly, Jenna exhibited enthusiasm following a lesson on vocabulary instruction: "I'm really excited to create a word rich environment in my class. I love learning new words and I want to pass this on to my students. I love all of the Pinterest activities.” Jenna's reflective response left a heartfelt feeling on the instructor's mind, but without specificity about the instructor's pedagogy, the evidence provided by this reflection only noted Jenna's enthusiasm and motivation for teaching vocabulary.

Collectively, visceral responses indicated excitement, enthusiasm, and motivation toward becoming teachers. Visceral responses left the instructor reflecting on pedagogical effectiveness and wondering how well course material was comprehended. 
[Type here]

Vulnerability. Beyond reflections that represented visceral thought lays a deeper sense of vulnerability. While still heavily focused on emotions, vulnerable responses went beyond a quick emotional response to become extended personal anecdotes. Data indicating vulnerable responses were individualistic and communicated directly to the instructor through concerns and perceived challenges. Vulnerable reflections focused on difficulty comprehending material, recognizing and admitting uneasiness, and attention to areas of professional development.

Stressful scenarios were voiced that focused on understanding course content in preparation for becoming a teacher. While beginning to tackle the process of completing a miscue analysis of a running record, Casey admitted, "I think the miscue analysis process is very helpful, but I think I need more practice.” Ariana relayed this sentiment, "my only concern is having enough practice before it is time for me to properly implement and analyze this method on my own." Similarly, uneasiness was communicated by Beth reflecting on a morphemic analysis lesson, "the class was helpful because morphemic analysis has never been my strongest area, but today really helped me better understand it all."

Another indication of vulnerability was uneasiness related to course assignment expectations. Harper shared hesitations about an assignment focused on the implementation of literature circles when she reflected "at the beginning of the literature circle portion of class I was extremely nervous because I was confused about how everything was supposed to work and blend together." Sherry also communicated concern for a course assignment, feeling "a little overwhelmed by the Content Area Topic Study project," yet later relayed "it will be a great project once I really dive into it." 
Vulnerability was also communicated as preservice teachers openly reflected upon their nervousness to apply course content to an authentic classroom setting. Avery projected, "it seems unreal that in one/two year(s) I will be responsible for students learning these standards." Kianna also expressed trepidation about her preparedness to be a teacher of reading when she openly admitted "comprehension is something that I struggled with in elementary and middle school." Vulnerability statements provided an avenue for the realization and admission of professional development while communicating with the instructor the complexity of making connections between learning theory and classroom practice.

Processing to comprehend course content. Responses focused on processing course content clarified learning and improved comprehension. Comprehending course content response types provided the instructor with insight into preservice teachers' thinking and acted as formative assessment. Responses highlighted comprehension of course material and how teaching methods could be implemented to teach comprehension strategies and skills.

Many retold comprehension in ways comprehensible to them, such as Sandra's description, "comprehension is the purpose of reading, understanding written language. There are many strategies like visualizing, questioning, and determining importance that give students the skill they need to comprehend text." Jenna similarly grappled with defining comprehension, yet her definition included the consideration of background knowledge, where "comprehension is reading a text, thinking about information from the text, mixing it with what you already know, and developing understanding from all of that." 
Reflection about comprehension went beyond personalized definitions to include strategies for teaching comprehension. The importance of making comprehension strategies visible was emphasized by Jenna's mention of teacher-modeling during comprehension strategy instruction, "because much of comprehension is an internal process, it is important to use think-alouds when modeling for students." Others provided detailed descriptions of how to teach comprehension strategy instruction and emphasized how strategy instruction needs to be explicit and purposefully modeled in a step-by-step procedural manner. Sherry expanded on this notion of explicit modeling to teach comprehension, where "modeling a comprehension strategy requires explicit instruction, and should be a part of a coordinated strategy plan that caters to student and classroom comprehension needs."

Additional data showed reflection on designing and implementing higher-order questions. Marie justified the importance of carefully constructing questions by emphasizing "questions are so important to generate higher order thinking with students, so learning how to ask GOOD questions instead of pointless ones are going to be very helpful in our future classroom."

Responses focused on content learned in class acted as formative assessment. Camy reflected on the overview of comprehension strategies and skills, "today was really helpful and allowed me to learn some new comprehension strategies, which will be helpful for our lesson plans." Christy increased her understanding of reading purpose genres, where "doing the activity with all of the children books helped me get a good visual and understanding of what type of books are good to use with different genres." Overall, reflective responses focused on course content provided the instructor with 
[Type here]

visible evidence that preservice teachers were comprehending content to prepare for their role as teachers of reading.

Identity formation. The final aspect apparent in blog reflections included responses focused on preservice teachers' formation of their teacher identity. Engaging in authentic activities connected to K-5 classrooms invoked responses about the instructor's pedagogy and how the delivery of course content might inform future teaching. Marie was pleased to analyze an assessment report, "it's also nice that we did this as an activity [using assessment to guide instructional planning], instead of just seeing what it looks like and moving on." Harper echoed the benefit of completing an activity demonstrating how to use assessment to inform instruction where "having us actually do it was really helpful and allowed us to think of realistic activities." The instructor's technique to include practical teaching application activities was also noted by Sandra who expressed, "I find it really valuable to practice real-life teachery things! Planning how my day will be helps me ensure that I am meeting standards and seeing how I can incorporate reading into every part of the day."

Identity formation was shaped by questioning and inquiring about applying similar activities within their future classroom. For example, Stephanie shared "the literature circle was a really fun way to work reading into collaborative work. I plan to use literature circles in my future classroom." After being introduced to a story-friendly vocabulary book, Gretchen expressed that she "loved the Weighty Words book, I think that's a great idea for kids to construct meaning of the words within the text. I also liked how the writing was so descriptive, definitely a great teaching tool!" 
By engaging in authentic teaching activities in the university classroom, connections were made with field experiences, which contributed to the realization of becoming a teacher. In one activity, preservice teachers learned graphic organizers have a defined purpose, such as using a double bubble map to compare and contrast. Marie made a connection from her university classroom to her field experience:

I think graphic organizers are very important and need to be explicitly taught to students how to use and WHY they are using it. In my practicum, I saw that students know HOW to use one, but have no idea what they can use it for. They see it more as something they need to 'fill out' and that's it.

In another lesson, preservice teachers planned for reading instruction using a basal. Following this activity, Casey connected educational theory with teaching practice, "it was really awesome that we were able to practice with the teacher texts. I like when I can see a clear and direct connection between class and our classroom."

\section{Discussion}

This study demonstrates how the systematic use of a private blog led preservice teachers toward greater depths of reflection that resulted in an awareness and grappling toward their teacher identity. Though preservice teachers may not have been cognizant of the conceptualization of their teacher identity, their reflective thoughts and decisions communicated a process that may have ultimately contributed to the formation of their teacher identities. Teacher educators can contribute to teacher development by integrating intentional opportunities for reflection. "While we cannot learn or be taught to think, we do have to learn how to think well, especially how to acquire the general habits of reflecting" (Dewey, 1933, p. 35). The instructor's use of the blog following each class 
[Type here]

gave preservice teachers a structured time to reflect, while the private nature of the blog gave preservice teachers a space to make connections with field experiences.

Based on the findings in this study, we contend an important component to scaffolding reflection is becoming comfortable within the reflective space. The process of becoming comfortable with one's thinking includes generating reflective responses, such as those we identified as visceral thought. Visceral thought responses align with prior research on surface level reflection in teacher education (Bednar, 1991; Shoffner, 2008), yet visceral response types were important to preclude greater depths of reflection. The more preservice teachers engaged in the weekly reflection, visceral statements were reduced as vulnerability response types increased. Part of becoming a professional teacher includes being characterized by vulnerability (Kelchtermans, 2009). We believe the nature of the private blog contributed to vulnerable statements that led to teacher identity formation. Reflective responses of authentic meaning-making experiences allowed us to recognize preservice teachers' connections between the reading course and their field placements. Ultimately, preservice teachers generated inquiries and explored future teaching ideas, which contributed to their teaching philosophy and formation of teacher identity.

Analysis of surveys and blog responses allowed us to make connections between how preservice teachers think about reflection and how they use blogging as a method to reflect. Survey responses provided evidence of how preservice teachers perceive the experience of a written reflective practice and preservice teachers' blog responses illustrated how reflection helped grapple with becoming a classroom teacher. It is particularly interesting that the purposes of the reflective response writing activity, as 
[Type here]

reported in both surveys, were to report on what happened in-class and to evaluate an activity or lesson. We believe this consistency of preservice teachers' perception of reflection helps to explain why responses moved in a non-linear fashion through the emergent types of reflection: visceral thought, vulnerability, processing to comprehend course content, and identity formation. To demonstrate, we noticed reports on what happened in-class were illustrated by visceral responses and processing to comprehend course content; reflections followed a format stating, "this is what I learned," and "this is how I'm grappling with understanding what I learned." These responses allowed us to identify associations between preservice teachers' evaluations of an activity or lesson; vulnerable statements were a critical component to the conceptualization of teacher identity formations.

Findings from our study support the importance of making explicit connections to scaffold the evolution of reflective practice within teacher preparation programs (Bullough, 1989). To prepare teachers to be thoughtful and reflective educators (Dewey, 1933), instructors should gain an understanding of preservice teachers' perception and use of reflection (Roskos et. al, 2001) by collecting a baseline understanding of reflection. Our study supports that preservice teachers require systematic, explicit strategies to engage in higher levels of reflection (Shoffner, 2008). The use of the private blog provided preservice teachers with a professional development space to process course content and make connections with field experiences, which ultimately allowed for teacher identities to form.

Implications apply to teacher educators, specifically that reflective blogging can be a starting point to bridging educational theory with classroom practice. Findings from 
[Type here]

our study demonstrate how preservice teachers' conceptualization of their identity as an educator is a vulnerable task that evolves in a non-linear fashion. To cultivate identify formation, teacher educators should strive to scaffold the reflective process and normalize feelings of vulnerability in all aspects of a teacher preparation program.

\section{Limitations}

Since one of the researchers was also the instructor, it is possible personal bias may have presented itself regarding enthusiasm or interpretation of research. To help reduce potential bias, surveys regarding perceptions of the experience were kept anonymous and inductive analysis was conducted separately. Also, because preservice teachers had access to each other's journals in the private blog, it is possible this shared visibility may have impeded their willingness to fully disclose and reflect on course content, though we contend this private classroom space resulted in greater depths of reflection.

\section{Conclusion}

The results of this study show how explicit scaffolding of reflection and use of a private blog contributed to preservice teachers' ability to make connections between course content and field experiences, which led to the formation of teacher identities. Our findings that all preservice teachers' anticipate using a similar reflective strategy in their future teaching indicates acceptance of reflecting in online spaces. Findings suggest the use of a blog to cultivate reflective thinking should be considered by teacher preparation programs to investigate how this pedagogical strategy may make becoming a teacher a more transparent process that helps shape and actualize teacher identity formation. 
[Type here]

\section{References}

Argyris, C., \& Schön, D. A. (1974). Theory in practice: Increasing professional effectiveness. San Francisco, CA: Jossey-Bass.

Bednar, M. (1991). Teacher cognition: Preservice knowledge and reflections about the reading process. Paper presented at the $41^{\text {st }}$ National Reading Conference, Palm Springs, CA, Dec 3-7, 1991.

Bullough, R. V. (1989). Teacher education and teacher reflectivity. Journal of Teacher Education, 40(2), 15-21.

Creswell, J. W. (2013). Research design: Qualitative, quantitative, and mixed methods approaches. Thousand Oaks, CA: Sage Publications.

Dewey, J. (1910). How we think. Boston, MA: D. C. Heath \& Co.

Dewey, J. (1933). How we think: A restatement of the relation of reflective thinking to the educative process. Boston, MA: Houghton Mifflin.

Dillman, D. A. (2011). Mail and Internet surveys: The tailored design method--2007 Update with new Internet, visual, and mixed-mode guide. Hoboken, NJ: John Wiley \& Sons.

Feiman-Nemser, S. (2012). Teachers as learners. Cambridge, MA: Harvard Education Press.

Gay, G., \& Kirkland, K. (2003). Developing cultural critical consciousness and selfreflection in preservice teacher education. Theory Into Practice, 42(3), 181-187.

Grossman, P., McDonald, M., Hammerness, K., \& Ronfeldt, M. (2008). Dismantling dichotomies in teacher education. In M. Cochran-Smith, S. Feiman-Nemser, J. McIntyre, \& K. Demers (Eds.), Handbook of research on teacher education: 
[Type here]

Enduring questions in changing contexts (3rd ed.) (pp. 243-248). Philadelphia, PA: Taylor and Francis.

Hatch, J.A. (2002). Doing qualitative research in education settings. Albany, NY: State University of New York Press.

Kelchtermans, G. (2009). Who I am in how I teach is the message: Self-understanding, vulnerability and reflection. Teachers and Teaching: Theory and Practice, 15(2), 257-272.

Korthagen, F. A., Kessels, J., Koster, B., Lagerwerf, B., \& Wubbels, T. (2001). Linking practice and theory: The pedagogy of realistic teacher education. London, England: Routledge.

Mortari, L. (2012). Learning thoughtful reflection in teacher education. Teachers and Teaching: Theory and Practice, 18(5), 525-545.

NCATE. (2010). Transforming teacher education through clinical practice: A national strategy to prepare effective teachers. Washington, DC: National Council for Accreditation of Teacher Education.

Novakovich, J. (2016). Fostering critical thinking and reflection through blog-mediated peer feedback. Journal of Computer Assisted Learning, 32(1), 16-30.

Osterman, K. F., \& Kottkamp, R. B. (1993). Reflective practice for educators. Newbury Park, CA: Corwin Press.

Risko, V. J., Roskos, K., \& Vukelich, C. (2001). Prospective teachers’ reflection: Strategies, qualities, and perceptions in learning to teach reading. Literacy Research and Instruction, 41(2), 149-175. 
[Type here]

Roskos, K., Vukelich, C., \& Risko, V. (2001). Reflection and learning to teach reading: A critical review of literacy and general teacher education studies. Journal of Literacy Research, 33(4), 595-635.

Ross, D.D., Bondy, E., \& Kyle, D.W (1993). Reflective teaching for student empowerment. London, England: Macmillan Publishing Company.

Schön, D. (1983). The reflective practitioner: How professionals think in action. New York, NY: Basic Books.

Shoffner, M. (2008). Informal reflection in pre-service teacher education. Reflective Practice, 9(2), 123-134.

Shulman, L. S. (1986). Those who understand: Knowledge growth in teaching. Educational Researcher, 15(2), 4-14.

Stiler, G. M., \& Philleo, T. (2003). Blogging and blogspots: An alternative format for encouraging reflective practice among preservice teachers. Education, 123(4), 789-797.

Wang, Q., \& Woo, H.L. (2008). The affordances of blogs and discussion forums for learning: A comparative analysis. Educational Technology, 48(5), 34-38.

Yang, S.H. (2009). Using blogs to enhance critical reflection and community of practice. Educational Technology \& Society, 12(2), 11-21.

Zeichner, K. M. (2009). Teacher education and the struggle for social justice. New York, NY: Routledge.

Zeichner, K. M., \& Liston, D. P. (2013). Reflective teaching: An introduction. London, England: Routledge. 